\title{
Role of Alternative Splicing in Sex Determination in Vertebrates
}

\author{
Isabel Gómez-Redondo ${ }^{a}$ Benjamín Planells ${ }^{a}$ b Paula Navarrete ${ }^{a}$ \\ Alfonso Gutiérrez-Adán ${ }^{\text {a }}$ \\ aDepartamento de Reproducción Animal, INIA, Madrid, Spain; 'bSchool of Biosciences, University of Nottingham, \\ Nottingham, United Kingdom
}

\section{Keywords}

Alternative splicing · Gonad development · Isoforms · Sex determination - Vertebrates

\begin{abstract}
During the process of sex determination, a germ-cell-containing undifferentiated gonad is converted into either a male or a female reproductive organ. Both the composition of sex chromosomes and the environment determine sex in vertebrates. It is assumed that transcription level regulation drives this cascade of mechanisms; however, transcription factors can alter gene expression beyond transcription initiation by controlling pre-mRNA splicing and thereby mRNA isoform production. Using the key time window in sex determination and gonad development in mice, it has been reported that new non-transcriptional events, such as alternative splicing, could play a key role in sex determination in mammals. We know the role of key regulatory factors, like WT1(+/-KTS) or FGFR2(b/c) in pre-mRNA splicing and sex determination, indicating that important steps in the vertebrate sex determination process probably operate at a posttranscriptional level. Here, we discuss the role of pre-mRNA splicing regulators in sex determination in vertebrates, focusing on the new RNA-seq data reported from mice fetal gonadal transcriptome.

(c) 2021 S. Karger AG, Basel
\end{abstract}

\section{Introduction}

The essential role of alternative splicing (AS) on sex determination in Drosophila melanogaster has been extensively reported. In this species a cascade of splicing factors, including an autoregulatory splicing loop controlled by the Sex-lethal gene $(S x l)$, ultimately leading to a sex-specific expression of the Doublesex (Dsx) isoforms, is involved in different aspects of sexual differentiation and behavior [Salz, 2011]. However, our understanding of the role of post-transcriptional molecular mechanisms involved in vertebrates' sex determination is still at an early stage. The majority of eukaryote genes have multiple transcriptional mRNA isoforms that are molecules of different exon composition and length and may code for different forms of the corresponding protein. These isoforms may be produced from different transcriptional starting sites and terminated at different polyadenylation sites or could be a consequence of AS [Matlin et al., 2005]. AS refers to the mechanism by which different exons, introns, or portions of them composing a gene are included or excluded differentially to produce unique mRNAs from a single pre-mRNA. The main mechanisms by which a gene is alternatively spliced are depicted in Figure 1. The occurrence of such events results in an increase in the coding capacity within a spe-

Correspondence to:

Alfonso Gutiérrez-Adán, agutierr@inia.es 


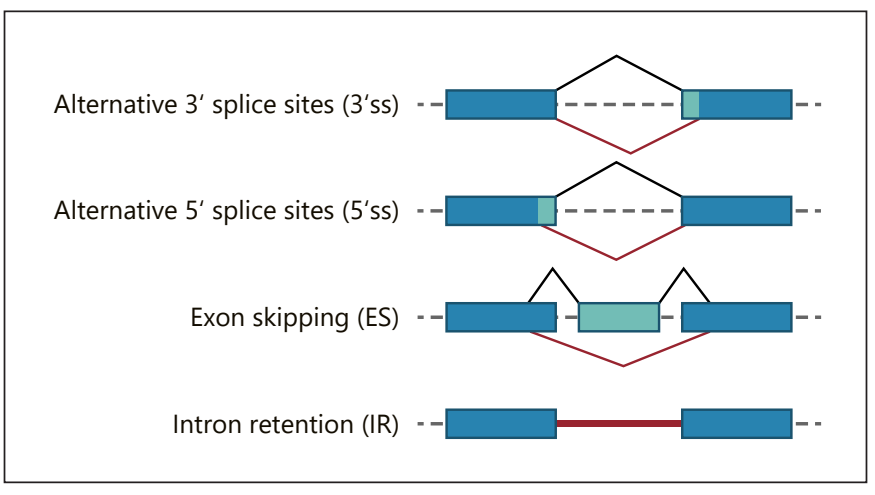

Fig. 1. Main types of alternative splicing: alternative $3^{\prime}$ splice sites $\left(3^{\prime} \mathrm{ss}\right)$, alternative $5^{\prime}$ splice sites ( $\left.5^{\prime} \mathrm{ss}\right)$, exon skipping (ES), and intron retention (IR). In each case, the black line represents the constitutive splicing and the red line the alternative splicing.

cific gene and therefore an increase of proteome complexity, constituting a ubiquitous regulatory mechanism of gene expression. AS has functions in developmental processes, regulating tissue and organ development and disease [Baralle and Giudice, 2017; Horiuchi et al., 2018; Gomez-Redondo et al., 2020]. AS may affect mRNA localization, stability, translation, or may change its reading frame, resulting in different protein isoforms with diverse functions and/or localizations [Wang et al., 2008]. Recently, 2 RNA-seq studies performed in mouse fetal gonads during the process of sex determination detected widespread stage- and sex-specific regulations of the transcript isoform usage during gonad development [Zhao et al., 2018; Planells et al., 2019]. Although the exact molecular consequences of these differential splicing events that were identified have not been unraveled yet, some AS has already been reported in genes that are known to have important functions in gonad development. A key gene in this process, the mammalian sexdetermining gene Sry, was recently characterized as a 2 -exon gene, which produces 2 isoforms related with sex [Miyawaki et al., 2020]. Other genes involved in sex determination which exhibit differential splicing are the Wilms' tumor suppressor gene $W t 1$, a transcriptional repressor and activator which participates in the sex-determining pathway by regulating Sry expression as well as other genes involved in sexual development [Hammes et al., 2001], the FGF9 receptor fibroblast growth factor receptor 2 ( $F g f r 2)$ which is the receptor that mediates the activity of Fgf9 in Sertoli progenitors during testis development [Kim et al., 2007; Rahmoun et al., 2017], and Lef1, a key mediator of the canonical WNT signaling pathway which is activated in ovarian embryonic development [Chassot et al., 2008]. Overall, these findings suggest an important regulatory role of AS in sex determination and early gonad development.

Even though most of the main genes related to sex determination in vertebrates are known, there is a lack of information about mRNA isoforms and AS variants involved in gonad development. These mechanisms are responsible for sex determination in some insects, including flies, honeybees, and wasps, [Bachtrog et al., 2014], and in some reptiles [Deveson et al., 2017]. Moreover, certain transcription factors important for sex determination in mammals, such as WT1 [Kreidberg et al., 1993], SRY, and SOX6, may control mRNA splicing by interacting with the splicing machinery [Little et al., 2000; Ohe et al., 2002; Rambout et al., 2018]. Furthermore, SOX9 has been shown to modulate either transcription or splicing of distinct sets of targets in colon tumor cells [Girardot et al., 2018]. Besides, during sex differentiation in mice, SOX9 not only directly regulates transcription of its target genes but also influences their mRNA splicing [Rahmoun et al., 2017]. A recent study has shown that 2 concurrent sex-specific AS forms within dmrt1 and cyp19a1 (gonadal aromatase) genes - genes largely recognized as the 2 opposing central players in sex-determining pathways in hermaphrodites and gonochoristic species [Domingos et al., 2018] - are central to sex determination and differentiation in some fish species [Domingos et al., 2018]. DMRT1 is a transcription factor expressed in both germ cells and Sertoli cells of the testis required for maintaining male sex determination by repressing the expression of female determining genes [Matson et al., 2011]. AS variants of $d m r t 1$ have been identified in ricefield eel [Huang et al., 2005], zebrafish [Guo et al., 2005], and catfishes [Raghuveer and Senthilkumaran, 2009]. Sex-biased expression of spliced isoforms has also been appreciated in other fish species, such as the European seabass (e.g., female-biased sox17 expression) [Navarro-Martin et al., 2009] and the protogynous ricefield eel (e.g., male-biased cyp17a1 expression) [Yu et al., 2003], and it suggests that some splicing mechanisms play a role in fish sex determination. In addition, AS and thermosensitive expression of $D M R T 1$ have been spotted during urogenital development in turtles, and DMRT1 isoforms have been found in crocodilians [Janes et al., 2014; Mizoguchi and Valenzuela, 2020], birds [Zhao et al., 2007], and fish [Guo et al., 2005; Huang et al., 2005; Domingos et al., 2018].

In this review, we describe recent discoveries that emphasize the role of AS in sex determination and differentiation in vertebrates. Table 1 displays a summary of al- 
Table 1. Summary of alternatively spliced genes involved in sex determination in different vertebrate species

\begin{tabular}{|c|c|c|c|c|}
\hline Class & Species & Gene/isoforms & Sex determination-related functions & Reference \\
\hline \multirow[t]{3}{*}{ Mammals } & Mus musculus & $w t 1$ (+KTS/-KTS) & $\begin{array}{l}\text { WT1(+KTS) acts as a transcriptional regulator of sex- } \\
\text { determining gene Sry, whereas WT1(-KTS) cooperates with } \\
\text { splicing factors, leading to the proliferation of somatic } \\
\text { cells of the gonadal ridges }\end{array}$ & $\begin{array}{l}\text { [Birk et al., 2000; } \\
\text { Hammes et al., 2001; } \\
\text { Wilhelm and Englert, } \\
\text { 2002; Val et al., 2007] }\end{array}$ \\
\hline & Mus musculus & Fgfr2 (FGFR2b/FGFR2c) & $\begin{array}{l}\text { Transcriptional factor that acts as a regulator of embryonic } \\
\text { development. Mutation of isoform FGFR2c causes sex } \\
\text { reversal }\end{array}$ & [Siggers et al., 2014] \\
\hline & Mus musculus & $\begin{array}{l}\text { Lef1 (exon 6-skipped Lef1/ } \\
\text { exon 6-included Lef1) }\end{array}$ & $\begin{array}{l}\text { Key mediator of the canonical WNT signalling pathway, } \\
\text { driving ovarian development and influencing testis } \\
\text { development. Exon } 6 \text { inclusion isoform is increased } \\
\text { exclusively in XX gonads during sex determination }\end{array}$ & [Zhao et al., 2018] \\
\hline \multirow[t]{6}{*}{ Fishes } & Danio rerio & $\begin{array}{l}\text { dmrt1 (Dmrt1a/Dmrt1b/ } \\
\text { Dmrt1c) }\end{array}$ & $\begin{array}{l}\text { Transcription factor that plays a key role in male sex } \\
\text { determination and differentiation as these isoforms are } \\
\text { preferentially expressed in testis. Loss of } d m r t 1 \text { is } \\
\text { associated with female sex determination }\end{array}$ & [Guo et al., 2005] \\
\hline & Lates calcarifer & dmrt1 (Dmrt1a/Dmrt1b) & $\begin{array}{l}\text { Preferential expression of Dmrt1a in testis, whereas } \\
\text { Dmrt1b is more expressed in the ovaries, both } \\
\text { contributing to gonad development }\end{array}$ & [Domingos et al., 2018] \\
\hline & Lates calcarifer & $\begin{array}{l}\text { cyp19a1 (short variant/ } \\
\text { full-length) }\end{array}$ & $\begin{array}{l}\text { Gene involved in gonad development. Ovaries express the } \\
\text { full-length gene, while testis show preferential expression } \\
\text { of a short variant that excludes exons } 1 \text { and } 2\end{array}$ & [Domingos et al., 2018] \\
\hline & Monopterus albus & $\begin{array}{l}\text { сур17 (Сур17a1/Сур17a2/ } \\
\text { Сур17b/Сур17c) }\end{array}$ & $\begin{array}{l}\text { Potentially involved in sex determination. Described as } \\
\text { differentially spliced during sex reversal }\end{array}$ & [Yu et al., 2003] \\
\hline & Monopterus albus & $\begin{array}{l}\text { dmrt1 (Dmrt1a/Dmrt1b/ } \\
\text { Dmrt1c/Dmrt1d) }\end{array}$ & $\begin{array}{l}\text { Gene involved in gonad development. Differential isoform } \\
\text { usage has been detected during gonadal transformation }\end{array}$ & [Huang et al., 2005] \\
\hline & Ictalurus punctatus & bcar1 (isoforms 1, 2, 3 and 4) & $\begin{array}{l}\text { Participates in sex determination through differential } \\
\text { expression of } 4 \text { alternative isoforms. Higher expression of } \\
\text { the transcript generated from a 3'ss AS event in exon } 8 \\
\text { leads to male gonad formation }\end{array}$ & [Bao et al., 2019] \\
\hline Birds & Gallus gallus & $\begin{array}{l}\text { Dmrt1 (Dmrt1a/Dmrt1c/ } \\
\text { Dmrt1g) }\end{array}$ & $\begin{array}{l}\text { Dmrt1a isoform shows higher expression in males and } \\
\text { Dmrt1c in the female gonads. Dmrt1g is specifically } \\
\text { expressed in the male gonads at the specific timing of sex } \\
\text { determination }\end{array}$ & [Zhao et al., 2007] \\
\hline \multirow[t]{5}{*}{ Reptiles } & Pogona vitticeps & $\begin{array}{l}\text { JARID2 (intron retention } \\
\text { isoforms) }\end{array}$ & $\begin{array}{l}\text { Gene involved in reptile temperature-dependent sex } \\
\text { determination and sex reversal. Intron retention of JARID2 } \\
\text { causes sex reversal in this species }\end{array}$ & [Deveson et al., 2017] \\
\hline & Pogona vitticeps & $\begin{array}{l}J M J D 3 \text { (intron retention } \\
\text { isoforms) }\end{array}$ & $\begin{array}{l}\text { Gene involved in reptile temperature-dependent sex } \\
\text { determination and sex reversal. Intron retention of JMJD3 } \\
\text { causes sex reversal }\end{array}$ & [Deveson et al., 2017] \\
\hline & Crocodylus palustris & $\begin{array}{l}\text { SOX9 (full-length/ } \\
\text { alternatively spliced) }\end{array}$ & $\begin{array}{l}\text { Gene involved in both genetic and temperature- } \\
\text { dependent sex determination. The unspliced transcript is } \\
\text { expressed specifically in males, whereas females express a } \\
\text { spliced isoform with an impaired transactivation domain }\end{array}$ & [Agrawal et al., 2009] \\
\hline & $\begin{array}{l}\text { Trachemys scripta and } \\
\text { Chelydra serpentina }\end{array}$ & $\begin{array}{l}\text { WT1 (isoform lacking exons } \\
4 \text { and 5) } \\
\text { (KTS+/KTS-) }\end{array}$ & $\begin{array}{l}\text { Essential player in gonad development and sex } \\
\text { determination. Differentially expressed isoforms during } \\
\text { the exact timing of temperature-dependent sex } \\
\text { determination }\end{array}$ & $\begin{array}{l}\text { [Spotila and Hall, 1998; } \\
\text { Rhen et al., 2015] }\end{array}$ \\
\hline & Chrysemys picta & $\begin{array}{l}\text { DMRT1 (isoform lacking } \\
\text { exons } 2 \text { and } 3 \text { ) }\end{array}$ & $\begin{array}{l}\text { Presents differential isoform usage during sex } \\
\text { determination, being their transcripts upregulated when } \\
\text { exposed to male-producing temperatures }\end{array}$ & $\begin{array}{l}\text { [Mizoguchi and } \\
\text { Valenzuela, 2020] }\end{array}$ \\
\hline
\end{tabular}


ternative spliced genes involved in sex determination in different vertebrate species which we are commenting on in this review hereinafter.

\section{Role of Alternative Splicing in Sex Determination in Non-Mammalian Vertebrates}

Gonad development is triggered by very diverse sex determination strategies. Non-mammalian vertebrates, reptiles, fishes, and birds have reported to show splicing mechanisms associated with gonadal differentiation and development.

Among other genes that have been identified as differentially spliced during sex determination, the doublesexand mab-3-related transcription factor number 1 (DMRT1) is of special interest, as it has a preserved role in sexual development [Raymond et al., 1998, 1999; Smith et al., 1999] and has been identified in diverse vertebrate species, such as mammals, fishes, birds, and reptiles (Table 1).

\section{Fishes}

Sex determination in fishes is an extremely diverse and labile process influenced by genetic and environmental factors [Devlin and Nagahama, 2002]. Most importantly, teleost fishes are the only vertebrates that undergo natural sex reversal, serving as a model to study sex-determining factors by means of the analysis of the molecular mechanisms on which one sex is transformed into the other.

Zebrafish (Danio rerio) is a juvenile hermaphrodite lacking discernible sex chromosomes, which is an excellent model for understanding the genetic basis for sex determination and differentiation. Sex determination in zebrafish has been described as a polygenic mechanism with different contributing loci such as $d m r t 1, a m h$, sox9, cyp19a1a, and foxl2a [Kossack and Draper, 2019; King et al., 2020]. Although the molecular mechanisms underlying sex determination in zebrafish are not fully understood, AS events have been expressed in pivotal genes. One of these genes is $d m r t 1$, which is known to be essential for male sexual development and fertility in zebrafish, while loss of $d m r t 1$ function is associated with female sex determination [Webster et al., 2017]. In particular, 3 different isoforms of the dmrt1 gene were identified in gonads, being predominantly expressed in testis [Guo et al., 2005].

A study in the species barramundi (Lates calcarifer), a protandrous hermaphrodite with initial male gonad development and subsequent change to ovaries, revealed the dimorphic expression of alternative splice variants of dmrt1 and cyp19a1 [Domingos et al., 2018]. The isoform Dmrtla, which harbours the DM domain, is testis specific, while Dmrtlb (which lacks this domain) is present in testis and ovaries. Regarding the aromatase cyp19a1, ovaries expressed the full-length mRNA which was absent in testis where exons 1 and 2 were alternatively spliced.

The analysis of the sex-determining and -differentiating mechanisms in the ricefield eel (Monopterus albus) revealed the involvement of splicing events. The ricefield eel is a freshwater fish that undergoes natural sex reversal from female to male. During the sex reversal process, this fish species expresses 4 isoforms of the cyp 17 gene in the gonads, suggesting the important role that the AS of cyp17 may play in sex determination [Yu et al., 2003]. Another study detected 4 isoforms of the dmrt1 gene specifically expressed in adult gonads. Two of the splice forms, $d m r t 1 a$ and $d m r t 1 b$, had an increasing expression from ovary to testis during the gonadal transformation that occurs in the sex change process [Huang et al., 2005].

A recent study on sex chromosomes of the channel catfish (Ictalurus punctatus) identified the dimorphic expression of an isoform of the breast cancer anti-resistance 1 gene (BCAR1) showing male-specific expression. This gene may participate in the sex determination process of this teleost fish through AS [Bao et al., 2019].

\section{Birds}

The process of sex determination in birds is genetically determined. Unlike mammals, female sex chromosomes are heterogametic $(\mathrm{ZW})$, whereas male ones are homogametic (ZZ). However, the molecular mechanisms underlying this process remain barely understood. One of the models that has been proposed for sex determination in birds is the "Z-dosage", being the dosage of Z-linked genes a mediator of sex determination. One of the Z-linked genes that is a strong candidate for this model is the Zlinked gene DMRT1 [Shan et al., 2000; Kuroiwa, 2018].

Chicken gene Dmrt1 undergoes AS, which generates 6 different transcripts during gonadal differentiation [Zhao et al., 2007]. The transcripts showing differential expression along the different stages are Dmrtla (which shows a higher expression in males at stage 31), Dmrt1c (higher expression in the female gonad), and Dmrt $1 g$ (specifically expressed in the male gonad at stage 31 ). Interestingly, stage 31 is considered the key time of sex gonadal differentiation.

Altogether, this transcriptional profile suggests an important role of splicing events in sex determination in 
birds. However, our understanding of the role of splicing in sex determination in birds is still very limited, and further studies are required to deepen our knowledge (Table 1).

\section{Reptiles}

The sex-determining mechanisms of reptiles are considerably diverse. The most common systems are the genetic control of sex determination and the environmental sex determination, in which sex is determined by the temperatures to which the embryos are exposed during development.

In reptiles, differential intron retention in Jumonji chromatin modifier genes has been implicated in temperature-dependent sex determination [Deveson et al., 2017]. The central bearded dragon (Pogona vitticeps) has a system of sex determination that involves the interplay of sex chromosomes (ZZ/ZW, the female being the heterogametic) and the temperature, where high temperatures during embryo development cause sex reversal of the ZZ genotype. Intron retention events in JARID2 and JMJD3 (Jumonji family members) have been identified in female central bearded dragon after suffering sex reversal [Deveson et al., 2017]. These splicing events do not take place in regular chromosomal male or females, therefore indicating the role of splicing in sex reversal in this species [Deveson et al., 2017]. Furthermore, another study identified the temperature-dependent sexual dimorphic expression of JMJD3 in the red-eared slider turtle [Ge et al., 2018]. Cell culture of lines from 2 different turtle species (red-eared slider turtle and common box turtle) also showed intron retention in JARID2, confirming the temperature-dependent AS [Haltenhof et al., 2020]. Moreover, JARID2 encourages PRC2 binding to its target loci, promoting its silencing [Kaneko et al., 2014; Sanulli et al., 2015]. In this model, the epigenetic landscape that would be modified as JARID2 is depleted from PRC2 as a consequence of AS (intron retention producing a truncated protein lacking the zinc finger DNA-binding domain), diminishing its recruitment to target genes and leading to canalization of the sex determination pathway to male [Deveson et al., 2017]. Interestingly, a closely related Jumonji family member, $J M J D 1 A$, participates directly in the regulation of $S R Y$, and a mutation in this gene causes male-to-female sex reversal in mice [Kuroki et al., 2013].

Analysis of SOX9, an evolutionary preserved transcription factor, known for its role in sex determination in a wide variety of species [Kent et al., 1996; Chaboissier et al., 2004], in the Indian Mugger (Crocodylus palustris) has revealed different patterns of expression in male and female embryos mediated by AS [Agrawal et al., 2009]. Indian Mugger SOX9 homolog, cpSox9, undergoes AS around its transactivation domain, generating splicing variants with impaired transactivation potential. An alternative spliced isoform of $c p$ Sox 9 was detected only in female embryos during the critical temperature-sensitive period, whereas males expressed an unspliced, full-length cpSox9 isoform [Agrawal et al., 2009]. This event has also been appreciated in mice, showing that AS is involved in both genetic and temperature-dependent sex determination [Agrawal et al., 2009].

Different AS mechanisms during sex determination have also been described in several species of turtles. Wilms' tumor gene WT1 is an essential player in gonad development and sex determination in vertebrates [Kreidberg et al., 1993; Shimamura et al., 1997]. Transcriptomic studies performed in the freshwater turtle (Trachemys scripta) and in the snapping turtle (Chelydra serpentina) have revealed AS isoforms of WT1, whose expression is different between male and female embryos at the crucial timing at which embryos are temperature sensitive [Spotila and Hall, 1998; Rhen et al., 2015]. Thus, AS of WT1 is also involved in the temperature-dependent sex determination mechanism of reptiles.

As stated above, the DMRT1 gene is highly preserved in both sequence and function, playing a pivotal role in sex determination in different vertebrates, including reptiles, where small amino acid changes in this gene have been associated with turnovers in sex determination [Janes et al., 2014]. In many reptilian species, DMRT1 is upregulated in male embryos, including the painted turtle (Chrysemys picta). In this species, different transcripts of $D M R T 1$ generated by AS have been detected during the sex-determination time point, both of them upregulated when exposed to male-producing temperatures, confirming its essential role for male sexual development in the painted turtle [Mizoguchi and Valenzuela, 2020]. However, further research is needed to elucidate why the number of DMRT1 isoforms that are produced varies in different taxa.

\section{Role of Alternative Splicing in Sex Determination in Mammals}

Some studies have reported that SRY and other SOX transcription factors may play a role in pre-mRNA splicing in mammals. Ohe et al. [2002] showed that SRY and the SOX protein SOX6 co-localize with splicing factors in the nucleus and found that SOX6-depleted nuclear ex- 
tracts presented impaired splicing activity. Interestingly, they also proved that nuclear extracts depleted of SOX6 recovered splicing activity by addition, not only of the recombinant HMG domain of SOX6 but also of recombinant SRY and the SOX9 HMG domain [Ohe et al., 2002]. One possible mechanism by which SRY and other SOX proteins participate in the process of pre-mRNA splicing is by interaction with RNA. A high degree of similarity between the SRY HMG domain and the RNA-binding domain of the hepatitis delta small antigen has been proved [Veretnik and Gribskov, 1999]. It might be possible that SRY and SOX proteins bind to RNA in the splicing machinery, changing its conformation and therefore modulating the different interactions (both protein-RNA and RNA-RNA) involved in spliceosome rearrangements during the process of pre-mRNA splicing [Lalli et al., 2003]. It is also possible that SRY and the SOX family members could act as trans-regulatory elements and bind to sequences in the proximity of splice sites, enhancing or repressing their use (similarly to the splicing regulators Sxl and Tra in Drosophila) [Lalli et al., 2003]. In addition, by using ChIP-Chip strategy, it has been reported that SRY targets 7 splicing genes (Samd10, Sfpq, Srsrf7, Syf2, $S f 3 b 2$, Tsen2, Sf3b5, and U2af2) at embryonic day E11.5 in mouse gonads [Li et al., 2014].

It has also been reported that SOX9 interplays with paraspeckle protein $\mathrm{P} 54 \mathrm{NRB}$, modulating the splicing process of the SOX9 downstream transcriptional target Col2a1 [Hata et al., 2008]. In a recent study, Rahmoun et al. [2017] found that SOX9 modulates transcription and sex-specific differential splicing by binding to specific genomic regions with preserved sequence motifs among mammals, controlling a preserved genetic program that includes a high number of the sex-determining genes [Rahmoun et al., 2017]. Girardot et al. [2018] examined global splicing changes by RNA-seq using DLD-1 and HEK293T cell lines in vitro and proved that SOX9 plays not only an important role as a transcription factor but also affects AS of many genes by associating with known splicing factors such as the exon junction complex (EJC) component Y14.

Regulation of Sox9 also depends on a feed-forward loop with fibroblast growth factor 9 (encoded by Fgf9, acting via its receptor FGFR2 and lipocalin-type prostaglandin D2 synthase, encoded by Ptgds). In fact, Colvin et al. [2001] reported male-to-female sex reversal in mice lacking Fgf9 and demonstrated its involvement in Sertoli cell development, gonadal cell proliferation, and mesonephric cell migration. The main function of this positive regulatory loop is to repress the wingless-related MMTV in- tegration site 4 (Wnt4) gene (which is considered to be a female promoting gene), initiating the differentiation of the bipotential genital ridge towards a testis. Kim et al. [2006] demonstrated that a lack of Wnt4 in XX gonads was sufficient to cause upregulation of $F g f 9$ and $S o x 9$ in the absence of Sry. Jameson et al. [2012] confirmed that the primary role of the Fgf signalling was to repress female-promoting genes, such as Wnt4. In that study, XY Fgf9/Wnt4 double mutants developed testes presenting both male somatic and germ cells. For testis development, not only is the expression of male genes, such as Sox9, essential, but also the active repression of the genes involved in the ovary fate (female pathway), such as Wnt4, is required. This highlights the interplay between the male and female genetic pathways during the early stages of the gonadal differentiation process. It has also been shown that conditional deletion of Fgf9 receptor FGFR2 in mice leads to a blockage of XY-specific gonad growth, disrupting testis differentiation and thus provoking sex reversal [Kim et al., 2007]. Another study in mice reported complete XY gonadal sex reversal after a constitutive hobbyhorse (hob) mutation of Fgfr2, supposed to affect both the FGFR2b and FGFR2c splice isoforms of the receptor [Siggers et al., 2014]. The role of the FGFR2c isoform in sex determination was later confirmed by Bagheri-Fam et al. [2017], who showed that this specific isoform represses FOXL2, and this is essential for male gonad development. Interestingly, only 4 isoforms of the 17 coding isoforms of $F g f r 2$ displayed high expression in females, indicating that, in addition to the role that some isoforms can have in male GSD [Bagheri-Fam et al., 2017], others may play a critical role in female GSD.

The murine wt 1 gene is composed of 10 exons and codes for more than 20 different proteins by the mechanisms of AS and alternative translation initiation [Sharma et al., 1994; Hammes et al., 2001]. WT1 is a zinc-finger protein that functions as a transcriptional regulator both as an activator [Lee et al., 1999] and a repressor [Menke et al., 1998]. Two isoforms of WT1 (produced by AS) have been proven to be involved in the process of sex determination (Fig. 2). An alternative splice site at the end of exon 9 produces these 2 different versions of the protein, which differ mainly in the inclusion or exclusion of 3 amino acids (KTS) between zinc fingers 3 and 4 . These 2 isoforms $(+\mathrm{KTS}$ and -KTS) play different roles in gonad development [Hammes et al., 2001]. In mice, the -KTS splice form participates, together with LHX9 and CITED2, in the upregulation of $S f 1$ expression, leading to the proliferation of somatic cells of the gonadal ridge [Birk et al., 2000; Wilhelm and Englert, 2002; Val et al., 2007]. Cited2 


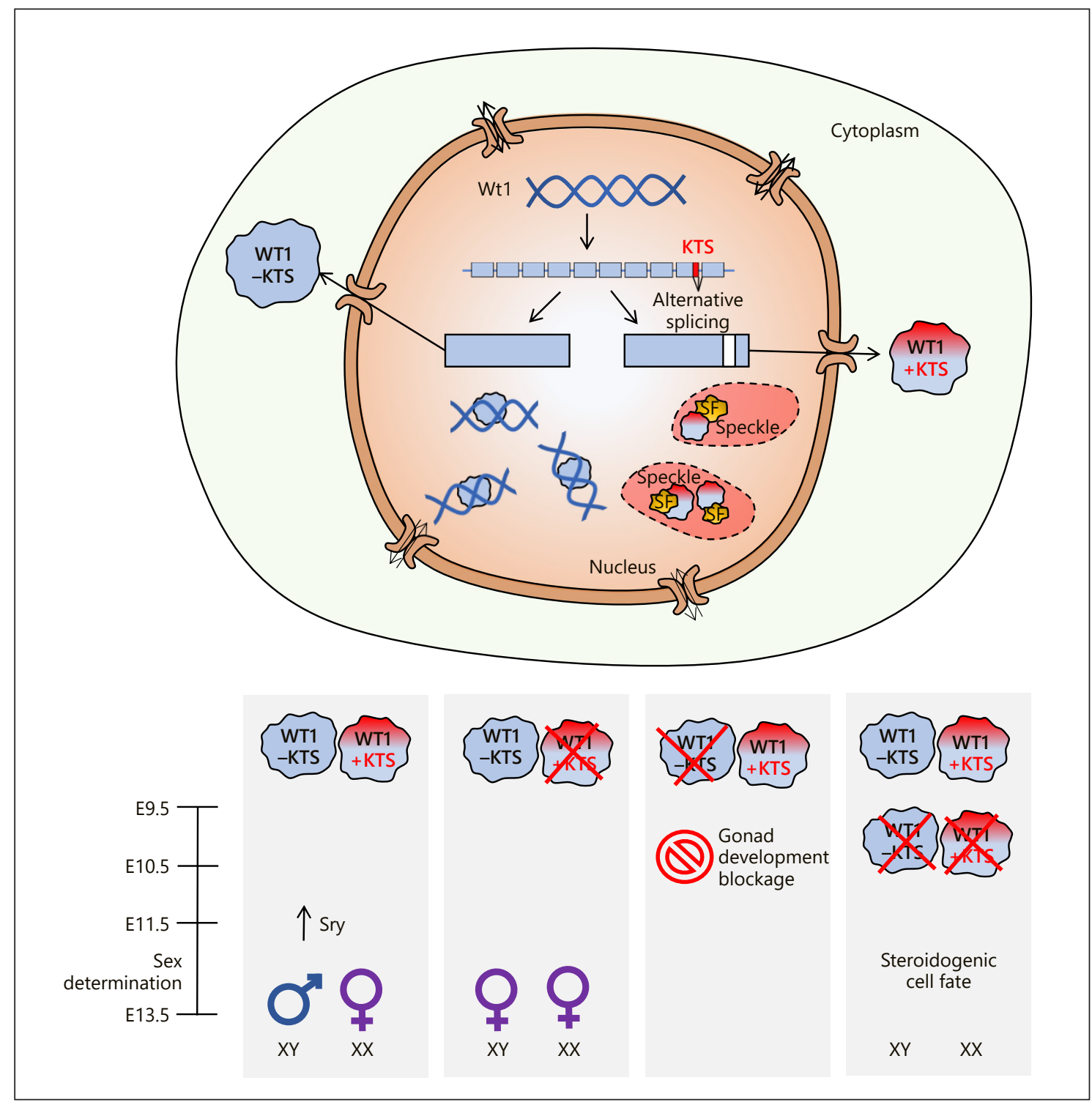

Fig. 2. Alternative usage of $3^{\prime}$ splice site in exon 9 of murine $w t 1$ produces 2 different isoforms with different cellular locations and functions in sex determination. These 2 isoforms differ in the inclusion or exclusion of 3 amino acids (KTS). WT1(-KTS) isoform is uniformly located in the nucleus and binds to DNA to act as a transcription factor, whereas WT1(+KTS) is usually localized in the nuclear speckles and binds to splicing factors. The bottom pan- el shows the effect of mutating these isoforms in mice embryo development. Deletion of WT1(+KTS) reduces the expression of the sex-determining gene Sry, causing sex reversal of XY embryos; in contrast, loss of WT1(-KTS) impairs embryo development regardless the sex of the embryo. Mutation of both isoforms after E10.5 allows gonadal growth but generates altered cell fate. encodes a non-DNA-binding protein that operates to obtain high levels of Sf1 and Sry expression, ensuring a robust activation of the male gonad development pathway [Buaas et al., 2009]. WT1(-KTS) isoforms have been also proposed to upregulate Dax1 expression in mice [Kim et al., 1999; Wilhelm and Englert, 2002]. On the other hand, the + KTS splice forms have been found to participate in
Sry regulation, and mice lacking this isoform show complete XY sex reversal [Hammes et al., 2001]. Moreover, the same WT1 isoforms (+KTS and -KTS) have also been reported in other species, such as cattle [Kent et al., 1995; Hunt et al., 2018; Planells et al., 2020].

The +KTS isoform has been found to localize in nuclear speckles (splicing factor compartments of the nucleus) 


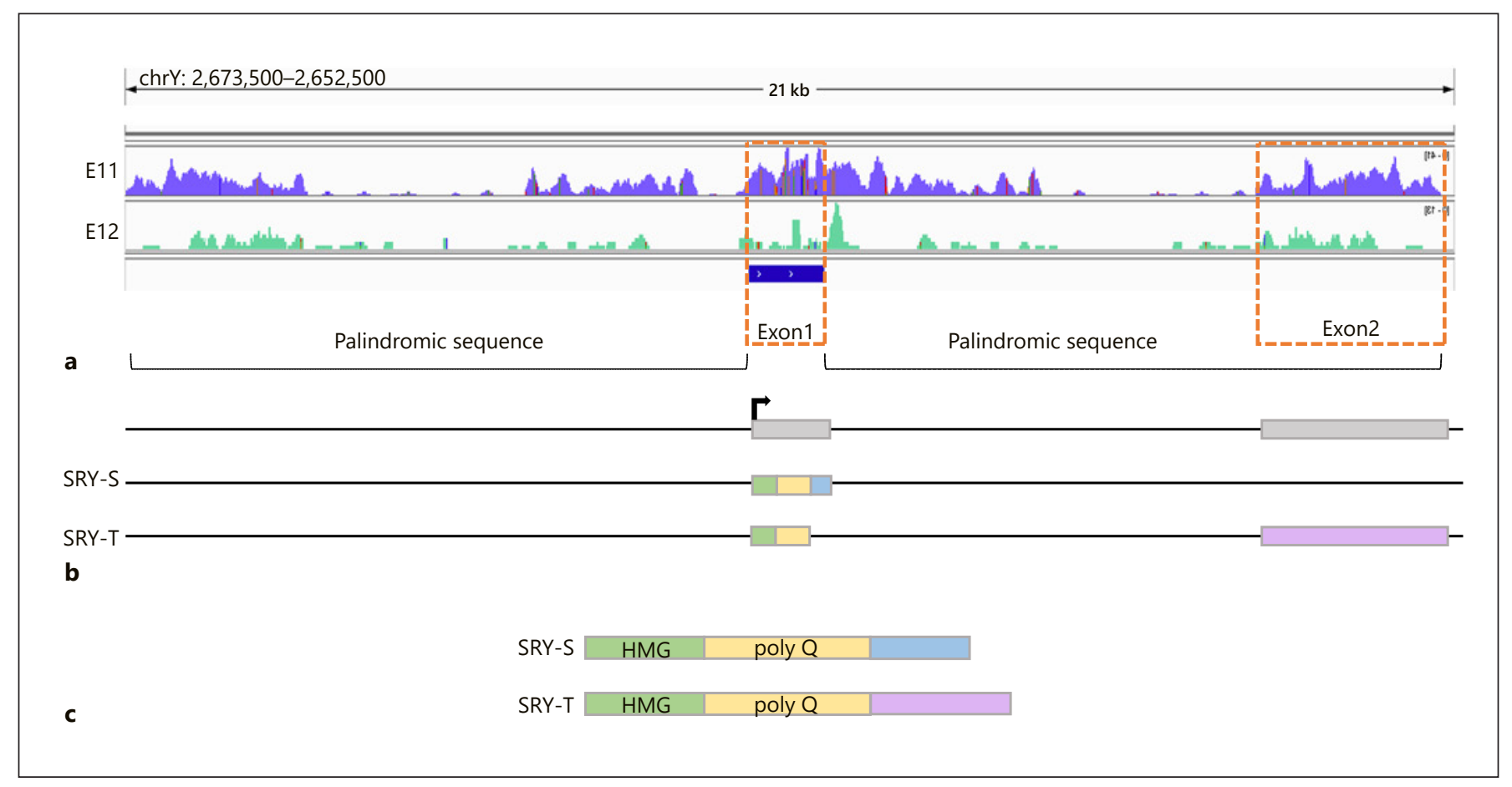

Fig. 3. Structure of the mouse Sry gene and its isoforms. a Visualization of the Sry region in IGV using the transcriptomic data of the study of Planells et al. [2019] and concretely corresponding to males PGCs in embryonic day 11 and embryonic day 12. The gene Sry is encoded in the (-) strand and is characterized by $2.8 \mathrm{~kb}$ of specific sequence and about $50 \mathrm{~kb}$ of flanking palindromic sequences. Exon 1 is present in the specific sequence, while exon 2 is

(Fig. 2). Davies et al. [1998] proved that this isoform is able to associate with the splicing machinery by interacting with the U2AF65 splicing factor [Davies et al., 1998]. Little et al. [2000] used a yeast 2-hybrid system for protein-protein interaction studies and found that human WT1 also interacts with WTAP [homolog of D. melanogaster female-lethal(2)d (fl2d)], which plays an important role in the splicing of $s x l$ and tra pre-mRNAs during the process of sex determination in the fly [Little et al., 2000]. They also evaluated the preservation of this gene against the mouse homolog which was found to be $>90 \%$ at both nucleotide and protein levels. The localization of this protein was evaluated by immunofluorescence and was found to co-localize with WT1 in the nucleoplasm and in the speckles, and with other splicing factors in the speckles [Little et al., 2000].

A recent study identified a second transcript of Sry, indicating that Sry is a 2 -exon gene that produces 2 isoforms: a 2-exon-derived functional protein driving testis development (SRY-T) and a single-exon-derived unsta- present in the $3^{\prime}$ palindromic sequence. $\mathbf{b}$ Exon-intron structure of the gene and its 2 different splice forms, SRY-S and SRY-T. In SRYT, exon 1 is spliced using an alternative donor site at the $3^{\prime}$ end and including exon 2, which is absent in SRY-S. c Isoforms obtained from the alternative splicing of Sry that contain a consensus sequence involving a HMG domain and a polyQ domain and differ in the C-terminal sequences.

ble isoform that does not participate in establishing the male fate (SRY-S) [Miyawaki et al., 2020] (Fig. 3). Mouse SRY contains a C-terminal transactivation domain endowed with a polyglutamine (poly-Q) region, which is necessary for testis determination [Fong et al., 2009]. These 2 variants of SRY (SRY-S and SRY-T), contain different amino acids after the poly-Q region. In nature, SRY-T, but not SRY-S, is sufficient to perform sex reversal in XX mice, indicating the predominant role of the Cterminal domain in male sex determination. Despite its essential function, this domain is defective in human $S R Y$ and even some mouse strains like the M. m. domesticus subspecies [Fong and Panchenko, 2010]. It has been suggested that the loss of homologies of the C-terminal transactivation domain of mouse $S R Y$ is because the variation in the C-terminus may disturb the spliceosome assembly and ultimately testicular failure [Zhang and Hou, 2021].

A study of splicing mutations in disorders of sex development in human also found that mutations in the HS$D 17 B 3$ and SRD5A2 genes, within potentially critical re- 
gions for splicing regulation, may jeopardize the correct biosynthesis of proteins that is important for the correct development of the gonads [de Calais et al., 2017]. Recently, Zhao et al. [2018] performed an RNA-seq analysis in mouse foetal-genital ridges during the process of sex determination from E10.5 to E13.5 and were able to detect sex-specific and stage-dependent differences of transcript isoform expression during gonad development [Zhao et al., 2018]. They reported female-specific regulation of Lef1 exon 6 when splicing, which could be involved in the enhanced WNT signalling activity in XX gonads. Exon 6-included full-length LEF1 may possess a higher transactivation capacity in female gonads, ensuring the foetal-ovarian development [Zhao et al., 2018].

Lastly, Mayère et al. [2021] performed single-cell RNA sequencing of XX and XY mouse germ cells between E9 and E16.5 and identified a sex-specific upregulation of genes associated with negative regulation of mRNA processing and increased intron retention, consistent with a reduction in mRNA splicing in XY testicular GCs by E13.5. The sexually dimorphic expression of genes related to mRNA processing (namely Tbrg4, Rbm38, and Supt6) was further confirmed by in situ hybridization at E14.5. Interestingly, these transcripts co-localized with the DAZL protein [Mayere et al., 2021].

Planells et al. [2019] performed RNA-seq of XX and $\mathrm{XY}$ mice gonads during sex determination at E11 and E12 (immediately before and after the Sry expression peak). Profiling of gene expression revealed an upregulation of genes involved in RNA splicing and mRNA processing ontology terms at E11, thus pointing to an active role of AS during sex determination. Most importantly, the study identified hundreds of specific isoforms related to gonadal sex determination that were differentially expressed, many of which showed no differences in the analysis of differentially expressed genes, highlighting the importance of AS during this process. They also identified hundreds of specific AS events modified at E11 and E12. Concretely, female E11 gonads featured preferential intron retention in genes related to the regulation of transcription, protein phosphorylation, protein transport, and mRNA splicing; exon skipping was also detected in female E11 gonads, taking place in genes related to chromatin repression. Overall, male and female gonads showed a large difference in intron retention right before the Sry peak, evidencing the significance of these events in tuning sex differences. Genes that have been associated with sex determination processes also showed AS differences between sexes; specifically, AS enrichment of Jarid2 was detected in E11 males, and Kmd3a showed differen- tial isoform usage in females. These observations point to AS as a post-transcriptional mechanism that controls sex determination of the bipotential foetal gonad [Planells et al., 2019]. These results are also in line with the findings made with Sox 9 knockout mice. This mutation causes a dysregulation of the splicing mechanism, affecting all types of AS and thus pointing to an important role of AS in sex determination [Rahmoun et al., 2017].

\section{Conclusions}

Given the role of AS in the increase of transcriptomic diversity without demanding greater genomic complexity, it is critical to investigate its role in sex determination in vertebrates.

\section{Conflict of Interest Statement}

The authors have no conflicts of interest to declare.

\section{Funding Sources}

This work was funded by grant RTI2018-093548-B-I00 from the Spanish Ministry of Science and Innovation. I.G.-R. and P.N. were supported by a pre-doctoral fellowship from the Spanish Ministry of Science, Innovation and Universities (BES-2016077,794 and PRE2019-088813, respectively).

\section{Author Contributions}

A.G.-A. planned the structure of the review, wrote the introduction, and supervised the manuscript. I.G.-R. was involved in summarizing the current state of understanding on the role of alternative splicing in sex determination in non-mammalian vertebrates, with the help of P.N. I.G.-R. also did the figures and contributed to the writing of the introduction. Table 1 was done by P.N. B.P. was involved in writing the part of alternative splicing in sex determination in mammals. All authors discussed the results and commented on the manuscript.

References

Agrawal R, Wessely O, Anand A, Singh L, Aggarwal RK. Male-specific expression of Sox9 during gonad development of crocodile and mouse is mediated by alternative splicing of its proline-glutamine-alanine rich domain. FEBS J. 2009;276:4184-96.

Bachtrog D, Mank JE, Peichel CL, Kirkpatrick M, Otto SP, Ashman TL, et al. Tree of Sex C: Sex determination: why so many ways of doing it? PLoS Biol. 2014;12:e1001899. 
Bagheri-Fam S, Bird AD, Zhao L, Ryan JM, Yong $\mathrm{M}$, Wilhelm $\mathrm{D}$, et al. Testis determination requires a specific FGFR2 isoform to repress FOXL2. Endocrinology. 2017;158:3832-43.

Bao L, Tian C, Liu S, Zhang Y, Elaswad A, Yuan $\mathrm{Z}$, et al. The $\mathrm{Y}$ chromosome sequence of the channel catfish suggests novel sex determination mechanisms in teleost fish. BMC Biol. 2019;17:6.

Baralle FE, Giudice J. Alternative splicing as a regulator of development and tissue identity. Nat Rev Mol Cell Biol. 2017;18:437-51.

Birk OS, Casiano DE, WassifCA, Cogliati T, Zhao L, Zhao Y, et al. The LIM homeobox gene Lhx9 is essential for mouse gonad formation. Nature. 2000;403:909-13.

Buaas FW, Val P, Swain A. The transcription cofactor CITED2 functions during sex determination and early gonad development. Hum Mol Genet. 2009;18:2989-3001.

Chaboissier MC, Kobayashi A, Vidal VI, Lützkendorf S, van de Kant HJ, Wegner M, et al. Functional analysis of Sox8 and Sox9 during sex determination in the mouse. Development. 2004;131:1891-901.

Chassot AA, Ranc F, Gregoire EP, Roepers-Gajadien HL, Taketo MM, Camerino G, et al. Activation of beta-catenin signaling by Rspo 1 controls differentiation of the mammalian ovary. Hum Mol Genet. 2008;17:1264-77.

Colvin JS, Green RP, Schmahl J, Capel B, Ornitz DM. Male-to-female sex reversal in mice lacking fibroblast growth factor 9. Cell. 2001;104 875-89.

Davies RC, Calvio C, Bratt E, Larsson SH, Lamond AI, Hastie ND. WT1 interacts with the splicing factor U2AF65 in an isoform-dependent manner and can be incorporated into spliceosomes. Genes Dev. 1998;12:3217-25.

de Calais FL, Smith LD, Raponi M, Maciel-Guerra AT, Guerra-Junior G, de Mello MP, et al. A study of splicing mutations in disorders of sex development. Sci Rep. 2017;7:16202.

Deveson IW, Holleley CE, Blackburn J, Marshall Graves JA, Mattick JS, Waters PD, et al. Differential intron retention in Jumonji chromatin modifier genes is implicated in reptile temperature-dependent sex determination. Sci Adv. 2017;3:e1700731.

Devlin RH, Nagahama Y. Sex determination and sex differentiation in fish: an overview of genetic, physiological, and environmental influences. Aquaculture. 2002;208(3-4):191-364.

Domingos JA, Budd AM, Banh QQ, Goldsbury JA, Zenger KR, Jerry DR. Sex-specific dmrt1 and cyp19al methylation and alternative splicing in gonads of the protandrous hermaphrodite barramundi. PLoS One. 2018;13: e0204182.

Fong JH, Panchenko AR. Intrinsic disorder and protein multibinding in domain, terminal, and linker regions. Mol Biosyst. 2010;6:1821-8.

Fong JH, Shoemaker BA, Garbuzynskiy SO, Lobanov MY, Galzitskaya OV, Panchenko AR. Intrinsic disorder in protein interactions: insights from a comprehensive structural analysis. PLoS Comput Biol. 2009;5:e1000316.
Ge C, Ye J, Weber C, Sun W, Zhang H, Zhou Y, et al. The histone demethylase KDM6B regulates temperature-dependent sex determination in a turtle species. Science. 2018;360:6458.

Girardot M, Bayet E, Maurin J, Fort P, Roux P, Raynaud P. SOX9 has distinct regulatory roles in alternative splicing and transcription. $\mathrm{Nu}$ cleic Acids Res. 2018;46:9106-18.

Gomez-Redondo I, Ramos-Ibeas P, Pericuesta E, Fernandez-Gonzalez R, Laguna-Barraza R, Gutierrez-Adan A. Minor splicing factors Zrsr1 and Zrsr2 are essential for early embryo development and 2-cell-like conversion. Int J Mol Sci. 2020;21:4115.

Guo Y, Cheng H, Huang X, Gao S, Yu H, Zhou R. Gene structure, multiple alternative splicing, and expression in gonads of zebrafish Dmrt1. Biochem Biophys Res Commun. 2005;330: 950-7.

Haltenhof T, Kotte A, De Bortoli F, Schiefer S, Meinke S, Emmerichs AK, et al. A conserved kinase-based body-temperature sensor globally controls alternative splicing and gene expression. Mol Cell. 2020;78:57-e4. e54

Hammes A, Guo JK, Lutsch G, Leheste JR, Landrock D, Ziegler U, et al. Two splice variants of the Wilms' tumor 1 gene have distinct functions during sex determination and nephron formation. Cell. 2001;106:319-29.

Hata K, Nishimura R, Muramatsu S, Matsuda A, Matsubara T, Amano K, et al. Paraspeckle protein p54nrb links Sox9-mediated transcription with RNA processing during chondrogenesis in mice. J Clin Invest. 2008;118: 3098-108.

Horiuchi K, Perez-Cerezales S, Papasaikas P, Ramos-Ibeas P, López-Cardona AP, LagunaBarraza R, et al. Impaired spermatogenesis, muscle, and erythrocyte function in U12 intron splicing-defective Zrsr1 mutant mice. Cell Rep. 2018;23:143-55.

Huang X, Guo Y, Shui Y, Gao S, Yu H, Cheng H, et al. Multiple alternative splicing and differential expression of dmrtl during gonad transformation of the rice field eel. Biol Reprod. 2005a;73:1017-24.

Hunt SE, McLaren W, Gil L, Thormann A, Schuilenburg H, Sheppard D, et al. Ensembl variation resources. Database (Oxford). 2018; 2018:bay119.

Jameson SA, Lin YT, Capel B. Testis development requires the repression of Wnt 4 by Fgf signaling. Dev Biol. 2012;370:24-32.

Janes DE, Organ CL, Stiglec R, O'Meally D, Sarre $\mathrm{SD}$, Georges A, et al. Molecular evolution of Dmrt1 accompanies change of sex-determining mechanisms in reptilia. Biol Lett. 2014;10: 20140809.

Kaneko S, Bonasio R, Saldaña-Meyer R, Yoshida $\mathrm{T}$, Son J, Nishino K, et al. Interactions between JARID2 and noncoding RNAs regulate PRC2 recruitment to chromatin. Mol Cell. 2014;53:290-300
Kent J, Coriat AM, Sharpe PT, Hastie ND, van Heyningen V. The evolution of WT1 sequence and expression pattern in the vertebrates. Oncogene. 1995;11:1781-92.

Kent J, Wheatley SC, Andrews JE, Sinclair AH, Koopman P. A male-specific role for SOX9 in vertebrate sex determination. Development. 1996; 122:2813-22.

Kim J, Prawitt D, Bardeesy N, Torban E, Vicaner $\mathrm{C}$, Goodyer $\mathrm{P}$, et al. The Wilms' tumor suppressor gene (wt1) product regulates Dax-1 gene expression during gonadal differentiation. Mol Cell Biol. 1999;19:2289-99.

Kim Y, Bingham N, Sekido R, Parker KL, LovellBadge R, Capel B. Fibroblast growth factor receptor 2 regulates proliferation and Sertoli differentiation during male sex determination. Proc Natl Acad Sci U S A. 2007;104: 16558-63.

Kim Y, Kobayashi A, Sekido R, DiNapoli L, Brennan J, Chaboissier MC, et al. Fgf9 and Wnt4 act as antagonistic signals to regulate mammalian sex determination. PLoS Biol. 2006;4: e187.

King AC, Gut M, Zenker AK. Shedding new light on early sex determination in zebrafish. Arch Toxicol. 2020;94:4143-58.

Kossack ME, Draper BW. Genetic regulation of sex determination and maintenance in zebrafish (Danio rerio). Curr Top Dev Biol. 2019;134 119-49.

Kreidberg JA, Sariola H, Loring JM, Maeda M, Pelletier J, Housman D, et al. WT-1 is required for early kidney development. Cell. 1993;74:679-91.

Kuroiwa A. Sex determination and differentiation in birds. In: KobayashiKitano KT, Iwao Y, Kondo M, editors. Reproductive and Developmental Strategies. Tokyo: Springer Japan; 2018. p. 391-405.

Kuroki S, Matoba S, Akiyoshi M, Matsumura Y, Miyachi $\mathrm{H}$, Mise N, et al. Epigenetic regulation of mouse sex determination by the histone demethylase Jmjd1a. Science. 2013;341: $1106-9$.

Lalli E, Ohe K, Latorre E, Bianchi ME, SassoneCorsi P. Sexy splicing: regulatory interplays governing sex determination from Drosophila to mammals. J Cell Sci. 2003;116:441-5.

Lee SB, Huang K, Palmer R, Truong VB, Herzlinger D, Kolquist KA, et al. The Wilms tumor suppressor WT1 encodes a transcriptional activator of amphiregulin. Cell. 1999; 98:663-73

Li Y, Zheng M, Lau YF. The sex-determining factors SRY and SOX9 regulate similar target genes and promote testis cord formation during testicular differentiation. Cell Rep. 2014; 8(3):723-33

Little NA, Hastie ND, Davies RC. Identification of WTAP, a novel Wilms' tumour 1-associating protein. Hum Mol Genet. 2000;9:2231-9.

Matlin AJ, Clark F, Smith CW. Understanding alternative splicing: towards a cellular code. Nat Rev Mol Cell Biol. 2005;6:386-98. 
Matson CK, Murphy MW, Sarver AL, Griswold MD, Bardwell VJ, Zarkower D. DMRT1 prevents female reprogramming in the postnatal mammalian testis. Nature. 2011;476:101-4.

Mayere C, Neirijnck Y, Sararols P, Rands CM, Stevant I, Kuhne F, et al. Single-cell transcriptomics reveal temporal dynamics of critical regulators of germ cell fate during mouse sex determination. FASEB J. 2021;35:e21452.

Menke AL, van der Eb AJ, Jochemsen AG. The Wilms' tumor 1 gene: oncogene or tumor suppressor gene? Int Rev Cytol. 1998;181: 151-212.

Miyawaki S, Kuroki S, Maeda R, Okashita N, Koopman P, Tachibana M. The mouse Sry locus harbors a cryptic exon that is essential for male sex determination. Science. 2020;370: 121-4.

Mizoguchi B, Valenzuela N. Alternative splicing and thermosensitive expression of Dmrt1 during urogenital development in the painted turtle, Chrysemys picta. PeerJ. 2020;8:e8639.

Navarro-Martin L, Galay-Burgos M, Sweeney G, Piferrer F. Different sox17 transcripts during sex differentiation in sea bass, Dicentrarchus labrax. Mol Cell Endocrinol. 2009;299:24051.

Ohe K, Lalli E, Sassone-Corsi P. A direct role of SRY and SOX proteins in pre-mRNA splicing. Proc Natl Acad Sci U S A. 2002a;99:1146-51.

Planells B, Gómez-Redondo I, Pericuesta E, Lonergan P, Gutiérrez-Adán A. Differential isoform expression and alternative splicing in sex determination in mice. BMC Genomics. 2019;20:202.

Planells B, Gómez-Redondo I, Sánchez JM, McDonald M, Cánovas Á, Lonergan $\mathrm{P}$, et al. Gene expression profiles of bovine genital ridges during sex determination and early differentiation of the gonads $\dagger$. Biol Reprod. 2020;102:38-52.

Raghuveer K, Senthilkumaran B. Identification of multiple dmrt1s in catfish: localization, dimorphic expression pattern, changes during testicular cycle and after methyltestosterone treatment. J Mol Endocrinol. 2009;42:437-48.
Rahmoun M, Lavery R, Laurent-Chaballier S, Bellora N, Philip GK, Rossitto M, et al. In mammalian foetal testes, SOX9 regulates expression of its target genes by binding to genomic regions with conserved signatures. Nucleic Acids Res. 2017;45:7191-211.

Rambout X, Dequiedt F, Maquat LE. Beyond transcription: roles of transcription factors in pre-mRNA splicing. Chem Rev. 2018;118: 4339-64.

Raymond CS, Shamu CE, Shen MM, Seifert KJ, Hirsch B, Hodgkin J, et al. Evidence for evolutionary conservation of sex-determining genes. Nature. 1998;391:691-5.

Raymond CS, Kettlewell JR, Hirsch B, Bardwell VJ, Zarkower D. Expression of Dmrt1 in the genital ridge of mouse and chicken embryos suggests a role in vertebrate sexual development. Dev Biol. 1999;215:208-20.

Rhen T, Fagerlie R, Schroeder A, Crossley DA, Lang JW. Molecular and morphological differentiation of testes and ovaries in relation to the thermosensitive period of gonad development in the snapping turtle, Chelydra serpentina. Differentiation. 2015;89:31-41.

Salz HK. Sex determination in insects: a binary decision based on alternative splicing. Curr Opin Genet Dev. 2011;21:395-400.

Sanulli S, Justin N, Teissandier A, Ancelin K, Portoso M, Caron M, et al. Jarid2 methylation via the PRC2 complex regulates H3K27me3 deposition during cell differentiation. Mol Cell. 2015;57:769-83.

Shan Z, Nanda I, Wang Y, Schmid M, Vortkamp A, Haaf T. Sex-specific expression of an evolutionarily conserved male regulatory gene, DMRT1, in birds. Cytogenet Cell Genet. 2000;89:252-7.

Sharma PM, Bowman M, Madden SL, Rauscher FJ 3rd, Sukumar S. RNA editing in the Wilms' tumor susceptibility gene, WT1. Genes Dev. 1994;8:720-31.

Shimamura R, Fraizer GC, Trapman J, Lau YC, Saunders GF. The Wilms' tumor gene WT1 can regulate genes involved in sex determination and differentiation: SRY, Mullerian-inhibiting substance, and the androgen receptor. Clin Cancer Res. 1997;3:2571-80.
Siggers P, Carré GA, Bogani D, Warr N, Wells S, Hilton $\mathrm{H}$, et al. A novel mouse Fgfr2 mutant, hobbyhorse (hob), exhibits complete XY gonadal sex reversal. PLoS One. 2014;9:e100447.

Smith CA, McClive PJ, Western PS, Reed KJ, Sinclair AH. Conservation of a sex-determining gene. Nature. 1999;402:601-2.

Spotila LD, Hall SE. Expression of a new RNAsplice isoform of WT1 in developing kidneygonadal complexes of the turtle, Trachemys scripta. Comp Biochem Physiol B Biochem Mol Biol. 1998;119:761-7.

Val P, Martinez-Barbera JP, Swain A. Adrenal development is initiated by Cited 2 and Wt1 through modulation of Sf-1 dosage. Development. 2007;134:2349-58.

Veretnik S, Gribskov M. RNA binding domain of HDV antigen is homologous to the HMG box of SRY. Arch Virol. 1999;144:1139-58.

Wang ET, Sandberg R, Luo S, Khrebtukova I, Zhang L, Mayr C, et al. Alternative isoform regulation in human tissue transcriptomes. Nature. 2008;456:470-6.

Webster KA, Schach U, Ordaz A, Steinfeld JS, Draper BW, Siegfried KR. Dmrtl is necessary for male sexual development in zebrafish. Dev Biol. 2017;422:33-46.

Wilhelm D, Englert C. The Wilms tumor suppressor WT1 regulates early gonad development by activation of Sf1. Genes Dev. 2002;16 1839-51.

Yu H, Cheng H, Guo Y, Xia L, Zhou R. Alternative splicing and differential expression of P450c17 (CYP17) in gonads during sex transformation in the rice field eel. Biochem Biophys Res Commun. 2003;307:165-71.

Zhang Y, Hou L. Alternate roles of Sox transcription factors beyond transcription initiation. Int J Mol Sci. 2021;22:5949.

Zhao L, Wang C, Lehman ML, He M, An J, Svingen $\mathrm{T}$, et al. Transcriptomic analysis of mRNA expression and alternative splicing during mouse sex determination. Mol Cell Endocrinol. 2018;478:84-96.

Zhao Y, Lu H, Yu H, Cheng H, Zhou R. Multiple alternative splicing in gonads of chicken DMRT1. Dev Genes Evol. 2007;217:119-26. 